
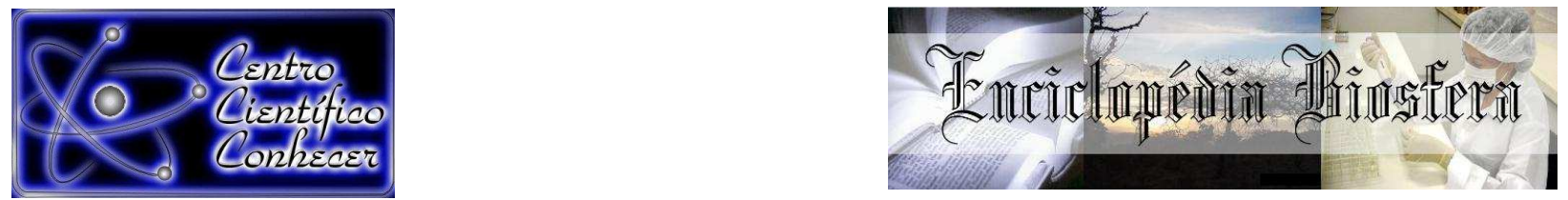

\title{
CARACTERIZAÇÃO DA PENEIRA MÉDIA E PERCENTUAL DE GRÃO TIPO MOCA DE Coffea Canephora DAS VARIEDADES BOTÂNICAS CONILON E ROBUSTA
}

Carolina Augusto de Souza1, Rodrigo Barros Rocha², Marcos Santana Moraes ${ }^{3}$, Victor Mouzinho Spinelli ${ }^{4}$, Enrique Anastácio Alves ${ }^{5}$.

${ }^{1}$ Engenheira agrônoma, Mestra em Desenvolvimento Regional e Meio Ambiente, Porto Velho-RO.

${ }^{2}$ Biólogo, D.Sc. em Genética e Melhoramento de Plantas, pesquisador da Empresa

Brasileira de Pesquisa Agropecuária - Embrapa Rondônia, Porto Velho-RO.

${ }^{3}$ Engenheiro-agrônomo, Mestrando em Ciências Ambientais-UNIR, Porto Velho-RO.

${ }^{4}$ Pós-Doutorando em Melhoramento Genético, FAPERO/Rondônia, Porto Velho-RO,

${ }^{5}$ Engenheiro-agrônomo, D. Sc em Engenharia Agrícola pesquisador da Empresa

Brasileira de Pesquisa Agropecuária - Embrapa Rondônia, Porto Velho-RO. enrique.alves@embrapa.com

Recebido em: 02/10/2017 - Aprovado em: 21/11/2017 - Publicado em: 05/12/2017 DOI: 10.18677/EnciBio_2017B14

\section{RESUMO}

Entre as diversas espécies de café identificadas, o Coffea arabica e o Coffea canephora, são as cultivadas comercialmente de maneira significativa. Na região Amazônica a principal espécie cultivada é o C.canephora que apresenta naturalmente duas variedades botânicas distintas o Conilon e o Robusta. Essas variedades possuem diferentes características em relação ao tamanho e a forma do grãos que são classificados de acordo com a retenção em peneiras com crivos de diferentes diâmetros. O objetivo desse trabalho foi quantificar ao longo de duas safras a peneira média (PM) e o percentual de grãos moca (PGM) de C.canephora. Para isso foram coletadas, amostras de 300 gramas de café de 112 clones, das variedades botânicas Conilon (68) e Robusta (18) e de híbridos intervarietais (26), provenitente do campo experimental da Embrapa Rondônia do município de Ouro Preto do Oeste - RO. Peneiras de crivos oblongos, de numeração 9 a 13 foram utilizadas para caracterizar os grãos tipo moca e as circulares de 12 a 19 para os grãos tipo chato. Observou-se que a PM não alterou sua média de um ano para o outro $(14,79-14,75)$, diferente do PGM que apresentou média de 32,5 no $1^{\circ}$ ano e 54,01 no $2^{\circ}$ ano. A PM é uma característica que foi pouca influenciada pelo ambiente em comparação com o PGM que apresentou uma baixa correlação ao longo do tempo. As variedades botânicas apresentam expressiva diversidade genética para PM que subsidia a seleção de novas cultivares que reúnam uma série de característica favoráveis.

PALAVRAS- CHAVE: Melhoramento genético, Qualidade, rondônia. 


\title{
CHARACTERIZATION OF THE AVERAGE SIEVE AND PERCENTAGE OF PEABERRY COFFE BEANS CONILON AND ROBUSTA BOTANICAL VARIETIES OF Coffea Canephora
}

\begin{abstract}
Among the various species of coffee were identified, the Coffea arabica and Coffea canephora, are the commercially grown significantly. In the Amazon region the main cultivated species is the C.canephora which features naturally two varieties of plants other than the Conilon and Robusta. These varieties have different characteristics in relation to the size and shape of the beans. It was separated into different sizes. The objective of this study was to quantify over two seasons the sieve medium (PM) and the percentage of bean mocha (PGM) of $C$. canephora. For this were collected, samples of 300 grams of coffee from 112 clones of varieties Conilon botanical (68) and (18) and of intervarietal hybrids (26) provenitente of experimental field of Embrapa Rondônia the municipality of Ouro Preto in the Oeste - RO. The screens of oblong sieves, numbering 9 to 13 were used to characterize the peaberry coffe beans and the circulars from 12 to 19 for the flat coffee bean. It was observed that the PM did't alter its average from one year to another (14,79-14,75), different from the MTPS that had an average of 32.5 in the 1 st year and 54.01 in the 2 nd year. The sieve is a characteristic of the material genotype and the percentage of grain mocha is a characteristic influenced by environment. The varieties of plants have great genetic diversity in the sieve average which subsidises the genetic improvement of the species.
\end{abstract}

KEYWORDS: Quality, Genetic improvement, Rondônia.

\section{INTRODUÇÃO}

O café possui o segundo maior rendimento econômico entre as commodity agrícolas, sendo que sua bebida é consumida por mais de dois bilhões de pessoas, número esse, que corresponde a $33 \%$ da população mundial (ROCHA et al.,2014). Segundo o levantamento da Conab (2017), o Brasil se manteve como o maior produtor e exportador de café mundial com uma produção de 49,67 milhões de sacas de $60 \mathrm{~kg}$, em que aproximadamente $75 \%$ são provenientes do cultivo da espécie Coffea arabica e $25 \%$ da espécie Coffea canephora (LIVRAMENTO et al., 2017).

Entre os estados brasileiros Rondônia se destaca na produção da espécie C.canephora, com a produção de 1,7 milhão de sacas de café no ano de 2016. A produtividade média de Rondônia é de aproximadamente 19 sacas por hectare. Segundo o levantamento da Conab (2017) houve uma diminuição de $6 \%$ da safra anterior devido a fatores climáticos, sendo que para a próxima safra existe uma expectativa de crescimento de $14 \%$ a $22 \%$.

O Coffea canephora,se caracteriza por apresentar plantas de duas variedades botânicas distintas, denominadas Conilon e Robusta (ROCHA et al., 2014). A variedade botânica Conilon se caracteriza por crescimento arbustivo, florescimento precoce, folhas alongadas e estreitas, caules ramificados, maior resistência à seca e maior suscetibilidade a doenças (SOUZA et al., 2015; RAMALHO et al., 2015). Enquanto que a variedade botânica Robusta possui maior vigor vegetativo, crescimento ereto, folhas e frutos de maior tamanho, maturação tardia, menor tolerância ao déficit hídrico e maior tolerância a pragas e doenças. Os híbridos intervarientais identificados naturalmente tem se destacado nas avaliações de campo (MARCOLAN; ESPINDULA, 2015). 
O tamanho dos grãos de café é classificado utilizando peneiras com base no tamanho e forma dos crivos (LAVIOLA et al., 2007; PEREIRA et al., 2016). Peneiras de crivos oblongos, de numeração 9 a 13 são utilizadas para caracterizar os grãos tipo moca e as circulares de 12 a 19 para os grãos tipo chato. Para a exportação é aceito o café com peneiras de № 13 a 20, havendo uma preferência pela peneira média acima de 15 (BONOMO et al., 2014:2017; CUSTÓDIO et al., 2015).

Mistura de grãos tipo chato e moca influenciam negativamente na qualidade da bebida, pois durante a torra do café os grãos maiores torram lentamente, enquanto os menores torram rapidamente e queimam, diminuindo a qualidade da bebida (CARVALHO SILVEIRA et al., 2015). Segundo Ferreira et al. (2013), a peneira média está associada a uma boa qualidade do café, que normalmente é negociado com maior valor de mercado. Laviola et al. (2006) salientam a importância da peneira para identificação de variedades com maior potencial produtivo.

Neste contexto o objetivo desse trabalho foi quantificar e caracterizar o tamanho dos grãos e o percentual de grãos tipo moca de 112 clones superiores das variedades botânicas Conilon, Robusta e de híbridos intervarientais, em avaliação no programa de melhoramento da Embrapa Rondônia, considerando os aspectos físicos da peneira média e do percentual de grãos moca.

\section{MATERIAL E MÉTODOS}

O experimento foi instalado no campo experimental de Ouro Preto do OesteRO, em novembro de 2011, a partir de mudas clonais utilizando o método de estarquia. O solo é um Latossolo Vermelho Escuro Eutrófico, de textura argilosa e bem drenado (SANTOS, 1999). O clima do município é do tipo Aw segundo a classificação de Köppen, sendo tropical úmido com estação chuvosa e estação seca bem definida. Observa-se as variáveis meteorológicas precipitação $(\mathrm{mm})$, o déficit hídrico $(\mathrm{mm})$, a temperatura máxima $\left({ }^{\circ} \mathrm{C}\right)$, a temperatura mínima $\left({ }^{\circ} \mathrm{C}\right)$ e a temperatura média $\left({ }^{\circ} \mathrm{C}\right)$ da cidade de Ouro Preto do Oeste-RO durante o período do experimento (Figura 1).

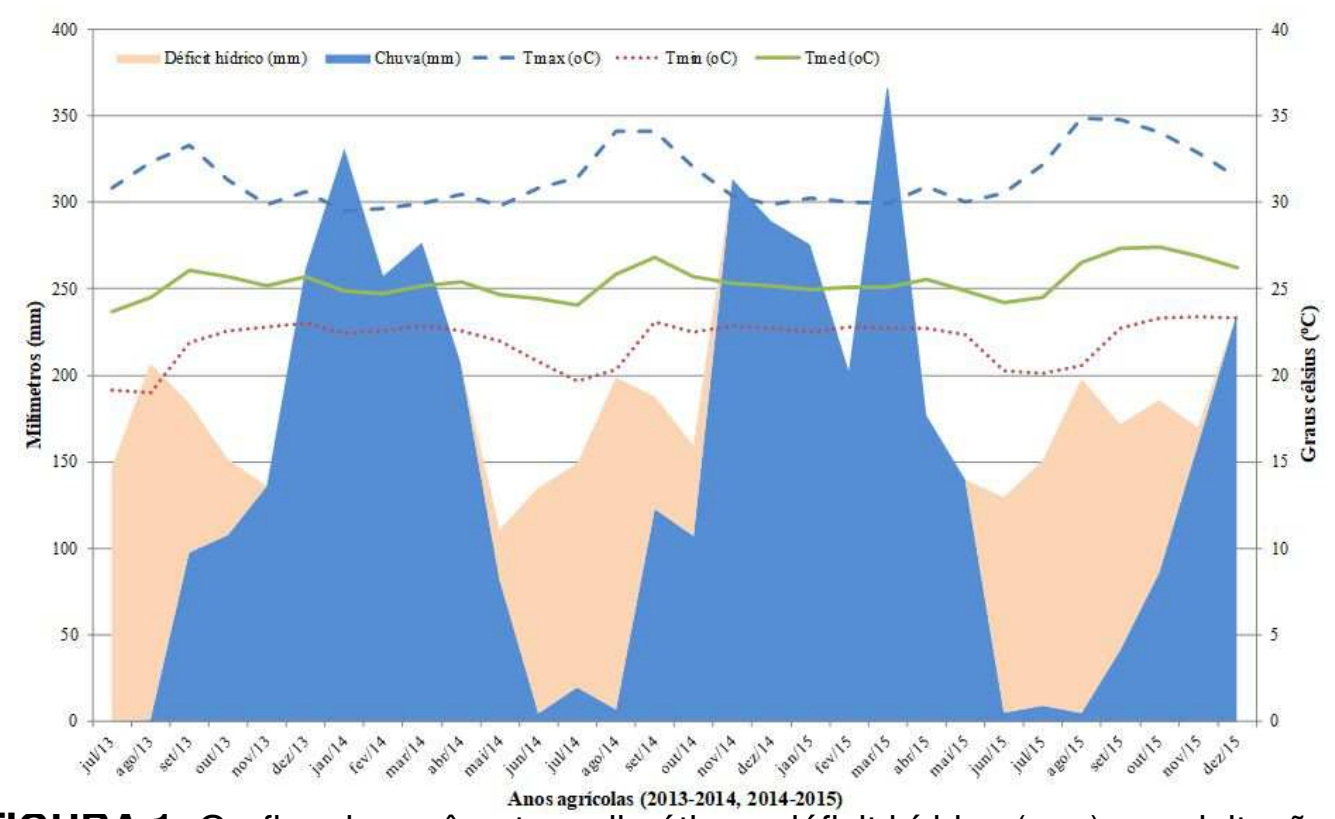

FIGURA 1. Grafico de parâmetros climáticos: déficit hídrico $(\mathrm{mm})$, precipitação $(\mathrm{mm})$ e temperaturas máxima, mínima e médias $\left({ }^{\circ} \mathrm{C}\right)$, dados correspondentes aos meses de julho de 2013 a dezembro de 2015 no município de Ouro Presto do Oeste - RO. Fonte: Souza et al. (2017). 
Nas safras de 2013-2014 e 2014-2015, foram colhidos frutos no estágio cereja, de 68 clones da variedade botânica Conilon, 26 clones da variedade botânica Robusta e 18 clones com característica hibridas (Conilon e Robusta) totalizando 112 clones. O espaçamento utilizadodo foi de $3 \times 2 \mathrm{~m}$ e o trato cultural foi realizado de acordo com Marcolan et al. (2009).

Foram coletadas separadamente amostras de $100 \mathrm{~g}$ de café beneficiado dos clones em avaliação. As estimativas de peneira média foram obtidas a partir da média ponderada do tamanho e o percentual de grãos retidos em cada peneira (KRUG, 1940). De forma que a peneira média é definida pelo percentual de grãos retidos em cada uma das peneiras em relação ao total, desconsiderando o resíduo que vai para o fundo das peneiras (grãos quebrados ou não desenvolvidos).

O tamanho de grãos e o percentual de grãos tipo moca foram avaliados individualmente utilizando conjunto de 14 peneiras diferentes, para a classificação conforme o formato dos grãos e a sua granulometria (SILVA et al., 2015). As peneiras de crivos oblongos, de numeração 9 a 13, foram utilizadas para reter os grãos tipo moca e as circulares de 12 a 19 para reter os grãos tipo chato.

A análise de variância foi interpretada para avaliar a significância dos efeitos de variedade botânica (VB), anos (ANOS) e da interação (VBxANOS). Para comparar as médias das variedades botânicas ao longo dos anos foi utilizado o teste de Tukey a $5 \%$ de probabilidade.

\section{RESULTADOS E DISCUSSÃO}

A analise de variância individual mostrou que a fonte de variação Variedades Botânicas (VB) apresentou diferenças significativas de acordo com o teste $\mathrm{F}$ a $1 \%$ de probabilidade, para peneira média (PM) e para o percentual de grãos moca (GM) nos dois anos avaliados. Esse resultado indica a existência de variabilidade genética entre as variedades botânicas Conilon, Robusta e híbridos intervarietais (Tabela 1). Ferrão et al. (2008b) também observaram efeito significativo de genótipos na avaliação da peneira média em 40 clones da variedade botânica Conilon ao longo de cinco anos. $\mathrm{Na}$ avaliação de 21 progênies de meios-irmãos de $C$. canephora Ivoglo et al. (2008) também observaram diferença significativa pelo teste $F$ no tamanho médio dos grãos.

No entanto, os valores do $\mathrm{CV}_{\mathrm{e}}$ para $\mathrm{GM}$ podem ser considerados altos, indicando maior efeito ambiental na expressão dessa característica. Na literatura são encontrados poucos trabalhos de caracterização da interação genótipos $x$ anos das características peneira media e percentual de grãos moca (FERRÃO et al., 2008b; BONOMO et al., 2014).

O teste de Bartlet não rejeitou a hipótese nula de igualdade entre as variâncias das análise individuais, pressuposição necessária para a análise conjunta (Tabela 1). A análise de variância conjunta indicou que a interação variedade botânica $x$ ano foi não significativa tanto para a peneira média quanto para 0 percentual de grãos moca. O efeito não significativo dessa interação indica consistência no comportamento dos genótipos ao longo dos anos, indicando que os efeitos de variedade botânica e de anos podem ser interpretados separadamente. Segundo Cruz et al. (2014) a interação genótipo x anos não significativa favorece a obtenção de ganhos com a seleção de plantas.

As estimativas do coeficiente de variação experimental $\left(C_{\mathrm{e}}\right)$ para peneira média e para grãos moca foram de $6,38 \%$ e de $38,18 \%$, respectivamente. Resultados semelhantes aos obtidos por Ferrão et al. (2008b) e Cilas et al. (2011) 
na avaliações da peneira média indicando uma boa precisão experimental para a avaliação.

A fonte de variação variedade botânica (VB) foi significativa tanto para PM, quanto para GM indicando a existência de diversidade genética entre as variedades botânicas Conilon, Robusta e híbridos intervarietais. A existência de variabilidade genética é condição primordial para a obtenção de ganhos com a seleção de plantas geneticamente superiores.

TABELA 1- Resumo das análises de variância da peneira média (PM) e percentual de grãos tipo moca (GM) avaliados em 112 genótipos das variedades botânicas Conilon (68) Robusta (26) e híbrido intervarientais (18), ao longo de duas safras 2013_2014 e 2014_2015, em Outro Preto do Oeste - RO.

\begin{tabular}{|c|c|c|c|c|c|}
\hline \multicolumn{6}{|c|}{ Análise individual } \\
\hline FV & GL & PM (2014) & PM (2015) & GM (2014) & GM (2015) \\
\hline Variedade botânica (VB) & 2 & $11,05^{\star *}$ & $13,55^{\star *}$ & $23,79^{* *}$ & $7,07^{* *}$ \\
\hline Resíduo & 109 & - & & & \\
\hline TOTAL & 111 & & & & \\
\hline Média geral & & 14,79 & 14,75 & 32,5 & 54,01 \\
\hline CVe (\%) & & 5,96 & 7,04 & 42,75 & 32,41 \\
\hline \multicolumn{6}{|c|}{ Análise conjunta } \\
\hline FV & GL & $\mathrm{PM} \mathrm{c}$ & onjunta & \multicolumn{2}{|c|}{ GM conjunta } \\
\hline Variedade botânica (VB) & 2 & & $2,38^{*}$ & \multicolumn{2}{|c|}{$25,85^{* *}$} \\
\hline Ano & 1 & & $33^{\text {ns }}$ & \multicolumn{2}{|c|}{$88,61^{* *}$} \\
\hline VB $\times$ Ano & 2 & & $64^{\text {ns }}$ & \multicolumn{2}{|c|}{$1,23^{\mathrm{ns}}$} \\
\hline Resíduo & 21 & & & & \\
\hline Total & 22 & & & & \\
\hline Média geral & \multicolumn{3}{|c|}{15,02} & \multicolumn{2}{|c|}{41,33} \\
\hline CVe (\%) & \multicolumn{3}{|c|}{6,38} & \multicolumn{2}{|c|}{38,18} \\
\hline Bartlett & \multicolumn{3}{|c|}{1,40} & \multicolumn{2}{|c|}{1,59} \\
\hline
\end{tabular}

FV: Fonte de variação, GL: grau de liberdade, F: teste F da análise de variância ", significativo a $1 \%$ e $5 \%$ de probabilidade, ${ }^{\text {ns. }}$ : não significativo, CV(\%): coeficiente de variação, Bartlett: Teste de homogeneidade de variâncias.

Por sua vez, o efeito de anos apresentou comportamento diferenciado entre as características avaliadas, tendo sido significativo para a GM e não significativo para PM. A significância do efeito de anos indica uma mudança no desempenho médio das plantas ao longo do tempo. Enquanto a PM apresentou pequena mudança na média de um ano para o outro, de 14,79 no ano de 2014 para 14,75 no ano de 2015, o GM mostrou um incremento na média de 32,50\% em 2014 para 54,01 em 2015 (Tabela 1). Segundo Krishnan (2012) e Munyuli, (2014), o aumento na incidência de grãos moca de um ano para o outro está associado a uma menor eficiência de polinização influenciada pela maior abundância de flores e ao maior porte das plantas no ano de maior produtividade.

A menor mudança na média da peneira média de um ano para o outro foi definida a predominância no controle genético dessa característica. Ferrão et al. ENCICLOPÉDIA BIOSFERA, Centro Científico Conhecer - Goiânia, v.14 n.26; p.160 
(2008a) observaram que o tamanho dos grãos em C. canephora apresenta controle genético predominante, indicando que a hibridação entre as variedades botânicas Conilon e Robusta pode ser utilizada para produzir uma planta que reúna maiores produtividades associada um maior tamanho de grãos. Ferrão et al. (2008b), relataram estimativas de herdabilidade acima de 0,8 na avaliação dessa característica em 40 clones no Estado do Espiríto Santo.

Uma maior peneira média é uma característica desejada pelos produtores de café uma vez que está associada há um maior rendimento e a uma maior qualidade da bebida (CORRÊA et al., 2016). O teste de média de Tukey $(P<0,05)$ mostrou diferenças significativas na peneira média entre as variedades botânicas Robusta e Conilon. Por sua vez os híbridos intervarietais não apresentaram diferenças significativas em comparação com a variedade botânica Robusta, que apresentou peneira média de 15,43 no primeiro ano e de 15,61 no segundo ano respectivamente (Tabela 2 ).

De maneira diferente, o teste de Tukey $(P<0,05)$ mostrou que não foi significativa a diferença entre a variedade botânica Conilon e os híbridos intervarietais para o percentual de grãos moca (Tabela 2). Em C. canephora, além da ocorrência de grãos tipo moca estar associado a fatores ambientais, tais como fatores nutricionais, climáticos e de estresse hídrico, essa espécie também apresenta mecanismos de autoincompatibilidade que impedem a autopolinização e a polinização entre plantas que compartilham o mesmo alelo do gene $S$, que governa a expressão dessa característica (PAIVA CUSTÓDIO et al., 2014; GARUMA et al., 2015). A menor ocorrência de grãos tipo moca na variedade botânica Robusta pode estar associada a um maior polimorfismo do gene $S$, que expressa $a$ autoincompatibilidade de $C$. canephora. Atualmente o percentual de grãos tipo moca não é considerado na avaliação da qualidade do café, entretanto é uma caracteristica desejada por proporcionar uma torrefação mais uniforme dos grãos (CARVALHO et al.,2013).

TABELA 2. Valores médios de peneira média $(P M)$ e percentual de grão tipo moca (GM) em 112 amostras de C.canephora, divididas entre as variedades botânicas Conilon (68) Robusta (26) e híbrido intervarientais (18), ao longo de duas safras 2013_2014 e 2014_2015, em Outro Preto do Oeste - RO.

\begin{tabular}{ccc}
\hline Variedades botânicas & PM 2014 & PM 2015 \\
\hline Conilon & $14,39 \mathrm{Ab}$ & $14,35 \mathrm{Ab}$ \\
Híbridos & $15,04 \mathrm{Aa}$ & $15,41 \mathrm{Aa}$ \\
Robusta & $15,43 \mathrm{Aa}$ & $15,61 \mathrm{Aa}$ \\
\hline Variedades botânicas & $\mathrm{GM} \mathrm{2014}$ & $\mathrm{GM} \mathrm{2015}$ \\
\hline Conilon & $38,07 \mathrm{Aa}$ & $57,01 \mathrm{Ba}$ \\
Híbridos & $35,08 \mathrm{Aa}$ & $58,92 \mathrm{Ba}$ \\
Robusta & $16,14 \mathrm{Ab}$ & $42,75 \mathrm{Bb}$
\end{tabular}

${ }^{a, b}$ Médias seguidas pelas mesmas letras maiúsculas na horizontal constituem grupo estatisticamente homogêneo de acordo com o teste de Tukey a $5 \%$ de probabilidade, Médias seguidas pelas mesmas letras minúsculas na vertical constituem grupo estatisticamente homogêneo de acordo com o teste de Tukey a 5\% de probabilidade. 
De acordo com Ferrão et al. (2007), a caracterização de genótipos de C. canephora deve considerar tanto o desempenho superior quanto à manutenção da superioridade ao longo do tempo. A dispersão dos valores de peneira média e do percentual de grãos moca nos anos de 2014 e 2015 mostram diferenças no comportamento dessas características ao longo do tempo (Figura 2). Enquanto a peneira média apresentou estimativa de coeficiente de determinação de 0,54 o percentual de grãos moca apresentou estimativa de 0,08 .

O coeficiente de determinação, que varia de 0 a 1, mensura o ajustamento dos valores observados a um modelo linear sendo que a raiz quadrada dessa estimativa equivale a estimativa de correlação linear entre os anos, que indica uma tendência das plantas que exibiram maior peneira média em um ano de também apresentar maior valor de peneira no ano seguinte. A menor correlação das avaliações ao longo do tempo da característica GM está associada a maior variação de natureza aleatória, que resulta em mudanças na resposta dos clones de um ano para o outro (Figura 2).
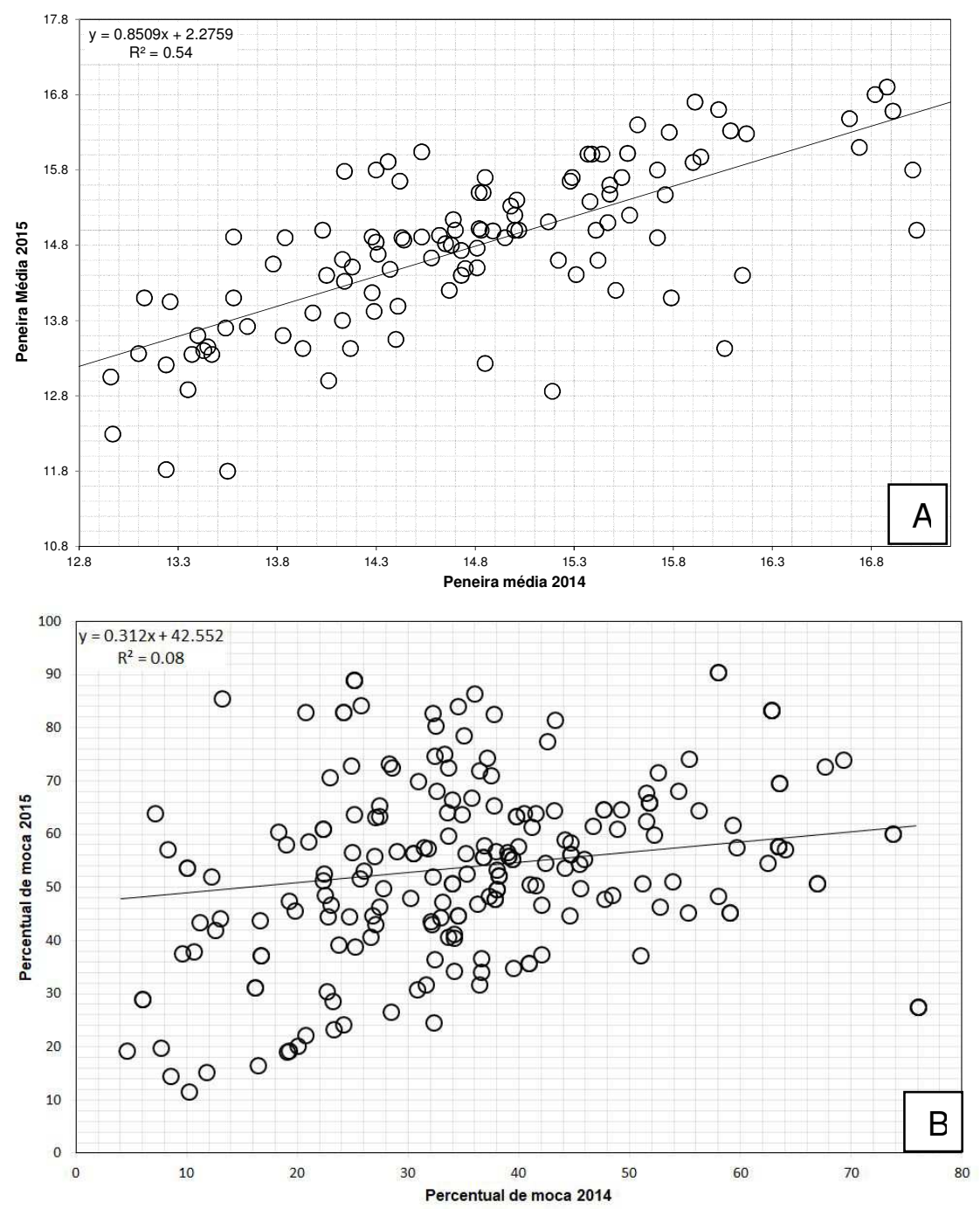

FIGURA 2- Distribuição dos valores das avaliações de peneira média (A), e do percentual e grãos tipo moca (B) avaliados nas safras de 2013_2014 e 2014_2015. 
A expressão diferenciada das características PM e GM indica que elas devem ser trabalhadas de forma diferente nos programas de melhoramento do cafeeiro. Por ter apresentando desempenho consistente ao longo do tempo a PM indica a possibilidade de obtenção de ganhos com a seleção enquanto o GM está associado a maior eficiência de polinização e maior variabilidade genética do plantio. O recurso genético existente subsidia o desenvolvimento de novas variedades que reúnam um conjunto de características favoráveis, associando maiores produtividades a maior qualidade do café. A hibridação das plantas com melhores características explorando a variabilidade genética e o vigor híbrido que se expressa entre as variedades botânicas, tem potencial para impactar no desenvolvimento de novas variedades.

\section{CONCLUSÃO}

A variedade botância Robusta e o Hibrido intervarietal apresentou peneira média superior à variedade botância Conilon nos anos avaliados. A peneira média é uma característica que foi pouca influenciada pelo ambiente em comparação com o percentual de grão moca. O maior coeficiente de determinação da peneira média indica consistência no desempenho dos genótipos ao longo do tempo.

As variedades botânicas apresentam expressiva diversidade genética para peneira média que subsidia a seleção de novas cultivares que reúnam uma série de característica favoráveis

\section{AGRADECIMENTOS}

Ao Conselho Nacional de Desenvolvimento Científico e Tecnológico (CNPq) pela concessão de bolsa e ao Consórcio Brasileiro de Pesquisa e Desenvolvimento do Café (CPC) pelo apoio financeiro.

\section{REFERÊNCIAS}

BONOMO, D. Z.; BONOMO, R.; PEZZOPANE, J. R. M.; DE SOUZA, J. M .Genótipos de café Conilon sob ajuste de diferentes coeficientes de cultura ajustados. Irriga, v. 22, n. 1, p. 236-248, 2017.Disponível em: <http://dx.doi.org/10.15809/irriga.2017v22n1p236-248>. doi: 10.15809/irriga.2017v22n1p236-248.

BONOMO, D. Z.; BONOMO, R.; PEZZOPANE, J. R. M.; DE SOUZA, J. M. Alternativas de manejo de água de irrigação em cultivos de conilon. Coffee Science, v. $9, \quad$ n. 4, p. 537-545, 2014. Disponível em https://www.coffeescience.ufla.br/index.php/Coffeescience/article/view/755/pdf_136

CARVALHO SILVEIRA, J. M.; DE LIMA JÚNIOR, S.; NASSER, M. D.; CORREIA, E. A.; JANOSKI, S. L. Produção e tamanho de grãos de café Coffea Arabica L (CV OBATÃ) sob fertirrigação. Revista Brasileira de Agricultura Irrigada, v.9, n.4, p.204. $2015 . \quad$ Disponível em: <http://search.proquest.com/openview/d9d0622097d3cdcaf2ca4ccc243d9819/1 ?pqorigsite $=$ gscholar $\& \mathrm{cbl}=2033446>$. doi. 10.7127/rbai.v9n400314

CARVALHO, G. R.; BOTELHO, C. E.; DE REZENDE, J. C.; FERREIRA, A. D.; DA CUNHA, R. L.; PEDRO, F. C. Comportamento de progênies $f 4$ de cafeeiros arábica, antes e após a poda tipo esqueletamento. Coffee Science, v. 8, n. 1, p. 33-42, 2013. 
<http://coffeescience.ufla.br/index.php/Coffeescience/article/view/323>.

CILAS, C.; BAR-HEN, A.; MONTAGNON, C.; GODIN, C. Definition of Architectural Ideotypes for Good Yield Capacity in Coffea canephora. Annals of Botany, v. 97, p. 405-411, $2006 . \quad$ Disponivel em: $<$ https://academic.oup.com/aob/article/97/3/405/291936/Definition-of-ArchitecturalIdeotypes-for-Good>. Doi: <https://doi.org/10.1093/aob/mcj053>

CONAB- COMPANHIA NACIONAL DE ABASTECIMENTO. Acompanhamento da safra brasileira café, v. 4 - Safra 2017, n.1 - Primeiro Levantamento, Brasília, p. 198, jan.2017.

Disponível [http://www.conab.gov.br/OlalaCMS/uploads/arquivos/17_01_17_09_06_50_boletim_ cafe_-_janeiro_de_2017.pdf]. Acesso em $17 \mathrm{de} \mathrm{fev,} 2017$.

CORRÊA, P. C. et al. Granulometria e torrefação na sorção de água em café conilon durante o armazenamento. Coffee Science, v. 11, n. 2, p. 221-233, 2016. Disponível em:

https://coffeescience.ufla.br/index.php/Coffeescience/article/view/1061/pdf_1061>

CRUZ, C. D.; CARNEIRO, P. S. C.; REGAZZI, A. J. Modelos biométricos aplicados ao melhoramento genético. 3. ed. rev. ampl. Viçosa, MG: UFV, 2014. v. 2. $668 \mathrm{p}$.

CUSTÓDIO, A. A. D. P.; LeMOS, L. B.; MINGOTTE, F. L. C.; POLLO, G. Z.; FIORENTIN, C. F.; ALVES, G. S. P. Qualidade do café sob manejos de irrigação, faces de exposição solar e posições na planta. Irriga, v. 20, n. 1, p. 177, 2015. Disponível em: <http://dx.doi.org/10.15809/irriga.2015v20n1p177>. doi: 10.15809/irriga.2015v20n1p177>.

FERRÃO, R. G.; FERRÃO, M. A. G.; FONSECA, A. F. A.; PACOVA, B. E. V. Melhoramento genético do Coffea canephora. In: Ferrão, R. G.; Fonseca, A. F. A.; Bragança, S. M.; Ferrão, M. A. G.; Muner, L. H. Café Conilon. Espírito Santo: Incaper, p.121-173, 2007.

FERRÃO, R. G.; FERREIRA, A.; CRUZ, C. D.; CECON, P. R.; FERRÃO, M. A. G.; et al. Inter-traitrelations for directandindirectselection in Coffee. Crop Breeding and Applied Biotechnology, v. 8, p.271-278, 2008a. Disponivel em: ,https://www.alice.cnptia.embrapa.br/alice/bitstream/doc/880534/1/Intertraitrelations.p $\mathrm{df}>$.

FERRÃO, R.G.; CRUZ, C.D.; FERREIRA, A.; CECON, P.R.; FERRÃO, M.A.G.; FONSECA, A.D.; CARNEIRO, P.D.; SILVA, M.D. Parâmetros genéticos em café Conilon. Pesquisa Agropecuária Brasileira, v. 43, n. 1, p. 61-69, 2008b. Disponivel em: $\quad<h t t p: / / w w w . s c i e l o . b r / s c i e l o . p h p ? s c r i p t=s c i$ arttext\&pid=S0100204X2008000100009>. doi: 10.1590/S0100-204X2008000100009

FERREIRA, A. D.; CARVALHO, G. R.; DE REZENDE, J. C.; BOTELHO, C. E.; REZENDE, R. M.; DE CARVALHO, A. M. Desempenho agronômico de seleções de café Bourbon Vermelho e Bourbon Amarelo de diferentes origens. Pesquisa 
Agropecuária Brasileira, v.48, n.4, p.388-394. 2013. Disponível em: em. <http://seer.sct.embrapa.br/index.php/pab/article/view/12228>.doi. 10.1590/S0100204X2013000400006

GARUMA, H.; BERECHA, G.; ABEDETA, C. Influence of Coffee Production Systems on the Occurrence of Coffee Beans Abnormality: Implication on Coffee Quality. Asian Journal of Plant Sciences, v. 14, n. 1, p. 40, 2015. Disponível em: http://docsdrive.com/pdfs/ansinet/ajps/0000/68073-68073.pdf

doi: 10.3923/ajps.2015.40.44

IVOGLO, M.G.; FAZUOLI, L.C.; OLIVEIRA, A.D.; GALLO, P.B.; MISTRO, J.C.; SILVAROLLA, M.B.; OMA-BRAGHINI, M. Divergência genética entre progênies de café robusta. Bragantia, v. 67, n. 4, p. 823-831, 2008.Disponivel em: <http://www.scielo.br/scielo.php?script=sci_arttext\&pid=S0006-

87052008000400003>. doi: 10.1590/S0006-87052008000400003

KRISHNAN, S.; Status of pollinators and their efficiency in coffee fruit set in a fragmented landscape mosaic in South India. Basic and Applied Ecology, v. 13, n. 3, p. 277-285, 2012. Disponivel em: http://www.sciencedirect.com/science/article/pii/S1439179112000291?via\%3Dihub >. Doi: https://doi.org/10.1016/j.baae.2012.03.007

KRUG, C.A. Hybridization of coffee. Jornal of Heredity, Washington, v. 26, n.8, p. 325-330, $1935 . \quad$ Disponivel em: <https://doi.org/10.1093/oxfordjournals.jhered.a104117>.doi:10.1093/oxfordjournals.j hered.a104117.

LAVIOLA, B. G., MAURI, A. L., MARTINEZ, H. E. P., ARAÚJO, E. F., NEVES, Y. P. Influência da adubação na formação de grãos mocas e no tamanho de grãos de café (Coffea arabica L.). Coffee Science, v. 1, n. 1, p. 36-42, 2007.Disponivel em:<http://coffeescience.ufla.br/index.php/Coffeescience/article/view/17>.

LIVRAMENTO, K. G.; BORÉM, F. M.; JOSÉ, A. C.; SANTOS, A. V.; DO LIVRAMENTO, D. E.; et al. Proteomic analysis of coffee grains exposed to different drying process. Food Chemistry, v.221, p.1874-1882. 2017. Disponível em: <http://www.sciencedirect.com/science/article/pii/S030881461631696X.> doi. 10.1016/j.foodchem.2016.10.069.

MARCOLAN, A. L.; M. C. ESPINDULA. Café na Amazônia. Brasília, DF: Embrapa. 2015. $474 \mathrm{p}$.

MARCOLAN, A. L.; RAMALHO, A. R.; MENDES, A. M.; TEIXEIRA, C. A. D.; FERNANDES, C. D. F.; COSTA, J. N. M.; ... VENEZIANO, W. Cultivo dos cafeeiros conilon e Robusta para Rondônia. Porto Velho, RO: (EMBRAPA Rondônia: Sistema de produção 33), 2009. 67 p.

MUNYULI, T. Influence of functional traits on foraging behaviour and pollination efficiency of wild social and solitary bees visiting coffee (Coffea canephora) flowers in Uganda. Grana, v. 53, n. 1, p. 69-89, 2014. Disponivel em: 
http://www.tandfonline.com/doi/abs/10.1080/00173134.2013.853831

doi:

http://dx.doi.org/10.1080/00173134.2013.853831.

PAIVA CUSTÓDIO, A.A.; FARIA, M.A.; REZENDE, F.C.; PAIVA CUSTÓDIO, A.A; GOMES, N.M. Irrigação por gotejo na maturação e classificação do café. IRRIGA, v. 19 , n. $3, \quad$ p. $488, \quad 2014 . \quad$ Disponivel em <http://dx.doi.org/10.15809/irriga.2014v19n3p488>. 10.15809/irriga.2014v19n3p488.

PEREIRA, T. C. V., SCHMIT, R., HAVEROTH, E. J., MELO, R. C. D., COIMBRA, J. L. M., GUIDOLIN, A. F., \& BACKES, R. L. Reflex of genotype x environment interaction on the genetic improvement of bean. Ciência Rural, v. 46, n. 3, p. 411417, 2016.Disponivel em: <http://dx.doi.org/10.1590/0103-8478cr20130998>. doi: 10.1590/0103-8478cr20130998.

RAMALHO, A. R., ROCHA, R. B., VENEZIANO, W., \& DOS SANTOS, M. M. (2015). Cultivar de cafeeiro Conilon BRS Ouro Preto: características agronômicas e agroindustriais. Embrapa Rondônia-Comunicado Técnico (INFOTECA-E), 2015.

ROCHA, R. B., SANTOS, D. V., RAMALHO, A. R., \& TEIXEIRA, A. L. Caracterização e uso da variabilidade genética de banco ativo de germoplasma de Coffea canephora Pierre ex Froehner. Coffee Science, v.8, n.4, p.478-485. 2014. Disponível em: <http://www.coffeescience.ufla.br/index.php/Coffeescience/article/view/504/pdf_66>.

SANTOS, P.L. Levantamento semi-detalhado dos solos do campo experimental de Ouro Preto D’Oeste. Embrapa Amazônia Oriental Documentos, Belém, n.8, p.138, 1999.

SILVA, L.C; MORELI, A.P; SIQUEIRA.A.J.H. Café: preparo, secagem e armazenamento. In:MARCOLAN, A.L; ESPINDULA, M.C.(Org.) Café na Amazônia. Brasília, DF : Embrapa, 2015. p. 400-424.

SOUZA, F.F; FERRÃO L.F.V; CAIXETA, E.T; SAKIYAMA, N.S; PEREIRA. A.A. OLIVEIRA, A.C.B. Aspectos gerais da biologia e da diversidade genética de Coffea canephora. In: MARCOLAN, A.L; ESPINDULA, M.C.(Org.) Café na Amazônia. Brasília, DF : Embrapa, 2015. p. 85-95.

SOUZA, C. A., ROCHA, R. B., ALVES, E. A., ESPINDULA, M. C., RAMALHO, A. R., et al. Componentes genéticos do desenvolvimento e maturação de frutos de Coffea canephora Pierre ex A. Froehner. Coffee Science, v. 12, n. 3, p. 355-364, 2017. Disponível $<$ https://coffeescience.ufla.br/index.php/Coffeescience/article/view/1295>.

em: 